\title{
Predisposing factors for dural tear in patients undergoing lumbar spine surgery
}

\author{
Yossi Smorgick, MD, ${ }^{1}$ Kevin C. Baker, PhD, ${ }^{2}$ Harry Herkowitz, MD, ${ }^{3}$ David Montgomery, $M D,{ }^{3}$ \\ Siddharth A. Badve, MD, ${ }^{3}$ Casey Bachison, MD, ${ }^{3}$ Steven Ericksen, MD, ${ }^{3}$ \\ and Jeffrey S. Fischgrund, MD ${ }^{3}$
}

${ }^{1}$ Department of Orthopedic Surgery and Spine Unit, Assaf Harofeh Medical Center, Zerifin, Israel, affiliated with the Sackler Faculty of Medicine, Tel-Aviv University, Tel-Aviv, Israel; and Departments of ${ }^{2}$ Orthopedic Research and ${ }^{3}$ Orthopedic Surgery, William Beaumont Hospital, Royal Oak, Michigan

\begin{abstract}
OBJECT The purpose of this prospective cohort study was to identify risk factors for incidental durotomies in lumbar spine surgery. The authors hypothesized that the incidence of durotomy would be higher in cases involving multiple operations.
\end{abstract}

METHODS The authors prospectively evaluated 523 patients who underwent lumbar and thoracolumbar spine surgery. They compared data on patients in whom a dural tear occurred and those in whom a dural tear did not occur. Data from patients in whom a dural tear occurred were compared with data from patients who did not experience durotomy. The data included basic demographic information, intraoperative data, and clinical information from a medical record review.

RESULTS One hundred thirty-one patients underwent discectomy and 392 patients underwent laminectomy. Among the 131 patients who underwent discectomy 6 patients had a dural tear. Among the 392 patients who underwent discectomy 49 patients had dural tear. Patients with incidental durotomy were older (mean $65 \pm 13$ vs $60 \pm 14$ years of age; $p=0.044$, t-test), and had longer surgery (146 \pm 59 vs $110 \pm 54$ minutes; $p=0.025$, t-test), compared with the patients without dural tear. The incidence of dural tear was more common in patients with a history of previous spine surgery $(p<$ 0.001).

CONCLUSIONS In patients who underwent lumbar and thoracolumbar spine surgery for degenerative problems, previous surgery and older age were found to be predisposing factors for dural tear.

http://thejns.org/doi/abs/10.3171/2015.1.SPINE13864

KEY WORDS dural tear; predisposing factors; revision surgery; laminectomy; microdiscectomy; lumbar

I NCIDENTAL tear of the dura and subsequent CSF leak is a common complication of lumbar spine surgery. Previous studies have found various factors affecting the incidence of incidental durotomy during lumbar spine surgery. Sin et al., in a prospective study, found that the incidence of durotomy was $16 \% .^{9}$ Their study of 76 patients found that patient age was a risk factor for incidental durotomy. However, a history of prior lumbar surgery and level of the surgeon's training did not affect the incidence of durotomy. ${ }^{9}$ Additional studies showed a higher percentage of lumbar dural tears in revision spine surgeries, ranging from $2.1 \%$ to $15.9 \%,{ }^{2,4,6,10}$ with a significant association between unintended durotomy and development of a new neurological deficit. ${ }^{12}$ However, these works were not a prospective comparison between 2 groups of patients, but were either retrospective or registry data. ${ }^{1}$

The purpose of the current study was to prospectively evaluate risk factors for incidental durotomies in lumbar spine surgery. We hypothesized that the incidence of a dural tear would be higher in cases involving repeated operations.

\section{Methods}

An institutional review board-approved protocol was developed at our institution (William Beaumont Hospital)

ABBREVIATION BMI $=$ body mass index.

SUBMITTED September 21, 2013. ACCEPTED January 14, 2015.

INCLUDE WHEN CITING Published online February 20, 2015; DOI: 10.3171/2015.1.SPINE13864.

DISCLOSURE Dr. Fischgrund reports that he is a consultant for Stryker and Relievant and owns stock in understand.com. He also reports that he is a board member of Baxano Surgical. No funds were received in support of this work. No benefits in any form have been or will be received from a commercial party related directly or indirectly to the subject of this manuscript. 
to prospectively compare data from patients in whom a dural tear occurred and those in whom dural tear did not occur during posterior lumbar and thoracolumbar spine surgery.

All patients who underwent spine surgery for degenerative conditions performed at our institution between January 2011 and June 2011 were included in the study. We excluded from this study patients treated for tumors, trauma, infections, deformity, and high-grade spondylolisthesis.

Basic demographic information, including age, sex, body mass index (BMI), and history of prior spine surgery, were compared between patients who had intraoperative dural tears and patients who did not have a dural tear. We also recorded the length of surgery (minutes), estimated blood loss during surgery $(\mathrm{ml})$, and amount of drainage (ml) and compared the data between the 2 groups. In all cases in which an incidental durotomy had occurred, one of the surgeons filled out a questionnaire that included data regarding the tear. The data that were obtained included the following: when the tear occurred during the procedure (exposure, decompression, or instrumentation), what instrument was in use when the tear happened, whether an attending or resident/fellow caused the tear, and the presence/absence of a patient-reported headache on postoperative Day 1.

For each case, the exact location of the dural tear was documented. The Wiltse system for reporting the size and location of lesions in the spine was implemented. ${ }^{13} \mathrm{On}$ the sagittal plane we defined superior, middle, and inferior locations for the vertebral segment. The superior area was equivalent to the suprapedicle and the pedicle level according to Wiltse system, while the middle area was equivalent to the infrapedicle level, and the inferior area was equivalent to the disc level according to the Wiltse system. In the coronal plane we defined medial and lateral zones. The medial zone was equivalent to the central canal zone, and the lateral zone was equivalent to the subarticular and foraminal zones according to Wiltse system.

Statistical analyses were performed using SigmaPlot software (version 11, Systat Inc.). T-tests were used to compare operative times, estimated blood loss, and drain output, with statistical significance defined as $\mathrm{p}<0.05$. Chi-square and Pearson product-moment tests were used when determining correlation between dural tears and intraoperative risk factors. Statistical significance was defined as $\mathrm{p}<0.05$ for these correlation tests.

\section{Results}

A total of 523 patients participated in our study; 131 patients underwent discectomy for relief of radicular pain secondary to a disc herniation and 392 patients underwent laminectomy for relief of neurogenic claudication symptoms due to spinal stenosis. Among the 131 patients who underwent discectomy, 6 patients had a dural tear (4.6\%). The mean operative time among patients who underwent discectomy ( $80 \pm 20$ minutes) and had dural tear was longer compared with the surgery time in patients who underwent discectomy and did not have dural tear $(45 \pm 15$ minutes; $p=0.002$ ). With respect to age, sex, estimated blood loss, BMI, and type of anesthesia (general vs spi-
TABLE 1. Main risk factors that were analyzed

\begin{tabular}{lc}
\hline \multicolumn{1}{c}{ Risk Factor } & p Value \\
\hline Older age & 0.044 \\
\hline Primary vs revision surgery & $<0.001$ \\
\hline Attending physician & $>0.05$ \\
\hline Use of instrumentation & 0.523 \\
\hline No. of levels decompressed & $>0.05$ \\
\hline
\end{tabular}

nal), there were no statistically significant differences between the 2 groups.

Among the 392 patients who underwent laminectomy, 49 patients had a dural tear (12.8\%). Patients with an incidental durotomy were older $(65 \pm 13$ vs $60 \pm 14$ years of age; $p=0.044)$ (Table 1$)$, had longer surgery $(146 \pm 59$ vs $110 \pm 54$ minutes; $p=0.025$ ), and had more drainage after surgery (771 \pm 380 vs $528 \pm 303 \mathrm{ml} ; \mathrm{p}=0.011)$ compared with patients without a dural tear. The incidence of dural tear was significantly more frequent in patients with a history of previous spine surgery (no history of prior spine surgery: 20 [7.2\%] of 276 patients; history of prior spine surgery: 29 [25\%] of 116 patients with history of spine surgery; $\mathrm{p}<0.001)$ (Tables 1 and 2). Twelve $(24.5 \%)$ of the 49 tears were caused by residents or fellows, with the remaining 37 caused by the attending surgeon $(\mathrm{p}<0.001)$. There was no significant difference between the different attending physicians with regard to the frequency of incidental durotomy $(\mathrm{p}>0.05)$ (Table 1). Most of the tears happened during the decompression (46 [94\%] of 49), while 2 tears (4.1\%) occurred during exposure and 1 tear $(2.0 \%)$ developed while implanting the cage for transforaminal lumbar interbody fusion. Most tears (31 [63\%] of 49) were caused by the Kerrison rongeur. There was no difference in the incidence of durotomy between patients who underwent decompression alone and patients who underwent decompression and instrumented fusion $(\mathrm{p}=0.523$; Tables 1,3 , and 4). For all tears, closure was attempted, and in most cases supplemental fibrin sealant was placed on the repair. Only 21 (43\%) of 49 patients with incidental durotomy reported having a headache the day after surgery.

\section{Discussion}

In this prospective study, we reviewed data for patients who underwent lumbar or thoracolumbar discectomy or laminectomy with or without instrumented fusion. Previ-

TABLE 2. Distribution of patients' surgical procedures and incidence of dural tear

\begin{tabular}{lcc}
\hline \multicolumn{1}{c}{ Surgical Procedure } & $\begin{array}{c}\text { Total No. } \\
\text { of Patients }\end{array}$ & No. w/ Dural Tear \\
\hline Microdiscectomy & 131 & 6 \\
\hline Laminectomy & 392 & 49 \\
\hline Laminectomy (primary) & 276 & 20 \\
\hline Laminectomy (revision) & 116 & 29 \\
\hline Laminectomy (instrumented) & 258 & 30 \\
\hline Laminectomy (noninstrumented) & 134 & 19 \\
\hline
\end{tabular}


TABLE 3. Incidence of dural tears in primary laminectomy cases with regard to the number of levels that were decompressed and the usage of instrumentation

\begin{tabular}{ccccccc}
\hline & \multicolumn{3}{c}{ No. of Patients } & & \multicolumn{2}{c}{ No. of Dural Tears } \\
\cline { 2 - 4 } No. of Levels & Total & Instrumented & Noninstrumented & & Total & Instrumented/Noninstrumented \\
\hline 1 & 93 & 57 & 36 & & 7 & $6 / 1$ \\
\hline 2 & 65 & 31 & 35 & 3 & $1 / 2$ \\
\hline 3 & 118 & 78 & 40 & 10 & $4 / 6$ \\
\hline
\end{tabular}

ous studies showed significant differences in the incidence of dural tears, usually with a lower incidence in retrospective studies. ${ }^{2,9}$ Wang et al., in a review of 641 consecutive patients who had undergone lumbar surgery, found a $14 \%$ incidence of dural tears. ${ }^{11}$ Sin et al..${ }^{9}$ in the only prospective study on this topic, found a $15.8 \%$ incidence of a dural tear in a series of 76 patients who underwent surgery for degenerative disorders of the spine. This incidence is similar to that observed in our study (4.6\% for discectomies and $12.8 \%$ for laminectomies).

Sin et al. ${ }^{9}$ prospectively studied 76 patients to determine risk factors for dural tears in a cohort of patients with degenerative spinal conditions. Two factors were statistically significant: experience of the surgeon (more tears were caused by a resident in training) and patient age $(p=0.044$ and $p=0.02$, respectively). However, the data that were obtained in their study did not support the argument that it is more common to cause a tear in revision surgery than in primary spine surgery. As in that study, our study shows a higher incidence of dural tears in older patients. This is probably due to degenerative changes occurring throughout the aging process, such as narrowing of the spinal canal and thickening of the ligamentum flavum. Additionally, the dura is often observed to be thinner in the elderly and in those patients with significant compression. While Sin et al. ${ }^{9}$ reported that residents in training caused more tears, our study demonstrated that 37 of the 49 dural tears were caused by the attending surgeon. We do not support the notion that more experienced surgeons tear the dura more frequently, but in some parts of the surgery one can predict difficulty in performing a decompression due to adhesions or dense scar tissue above the dura. These parts of the surgery are more likely to be performed by the attending surgeon, rather than the resident or fellow.

Unlike Sin et al., ${ }^{9}$ and similar to many other previous studies, ${ }^{3,5,8}$ we found that revision surgery is a risk factor for dural tear. This is most probably due to the loss of anatomical landmarks and the postoperative adhesions, which are common in revision cases. Based on our data we strongly recommend for the surgeon to be aware of the higher incidence for durotomy while conducting revision surgery and to be more cautious around the area covered with dense scar tissue.

Our study did not demonstrate a difference in the incidence of dural tear between patients who underwent decompression alone and patients who had decompression and instrumented fusion. However, as previously shown, 3,5 patients who underwent discectomy had a significantly lower incidence of dural tear than patients who underwent laminectomy. Of the 131 patients who underwent discectomy, only 6 patients had a dural tear. This low number does not allow us to draw any conclusions, but it is worth mentioning that one of the patients with a dural tear had a conjoined nerve root. Lotan et al. ${ }^{7}$ demonstrated that the incidence of a conjoined nerve root is 5.8\% for all microdiscectomies performed. We did not encounter such a high incidence, but we believe that suspecting a conjoined nerve root preoperatively is beneficial for avoiding the risk of intraoperative dural tear.

We were not able to demonstrate a specific spinal location in which dural tears tend to happen more frequently. Although we prospectively evaluated a large number of patients, there was no region of the spine that was significantly more represented in terms of the number of dural tears. This may be due to the fact that dural tears happened for different reasons and many tears are due to adhesions and scarring that can appear in different regions across the dural sac.

\section{Conclusions}

The incidence of dural tear was higher in patients who underwent laminectomy than in those who underwent microdiscectomy. Previous surgery and older age were found to be predisposing factors for dural tear. We recommend that spine surgeons be aware of these risk factors for incidental durotomy while operating.

TABLE 4. Incidence of dural tears in revision laminectomy cases as a function of the number of levels that were decompressed and the usage of instrumentation

\begin{tabular}{ccccccc}
\hline & \multicolumn{4}{c}{ No. of Patients } & & No. of Dural Tears \\
\cline { 2 - 3 } \cline { 6 - 7 } No. of Levels & Total & Instrumented & Noninstrumented & & Total & Instrumented/Noninstrumented \\
\hline 1 & 39 & 31 & 8 & 8 & $4 / 4$ \\
\hline 2 & 37 & 29 & 8 & 8 & $6 / 2$ \\
\hline 3 & 40 & 32 & 8 & 13 & $9 / 4$ \\
\hline
\end{tabular}




\section{References}

1. Baker GA, Cizik AM, Bransford RJ, Bellabarba C, Konodi MA, Chapman JR, et al: Risk factors for unintended durotomy during spine surgery: a multivariate analysis. Spine J 12:121-126, 2012

2. Cammisa FP Jr, Girardi FP, Sangani PK, Parvataneni HK, Cadag S, Sandhu HS: Incidental durotomy in spine surgery. Spine (Phila Pa 1976) 25:2663-2667, 2000

3. Deyo RA, Cherkin DC, Loeser JD, Bigos SJ, Ciol MA: Morbidity and mortality in association with operations on the lumbar spine. The influence of age, diagnosis, and procedure. J Bone Joint Surg Am 74:536-543, 1992

4. Guerin P, El Fegoun AB, Obeid I, Gille O, Lelong L, Luc S, et al: Incidental durotomy during spine surgery: incidence, management and complications. A retrospective review. Injury 43:397-401, 2012

5. Kalevski SK, Peev NA, Haritonov DG: Incidental dural tears in lumbar decompressive surgery: incidence, causes, treatment, results. Asian J Neurosurg 5:54-59, 2010

6. Khan MH, Rihn J, Steele G, Davis R, Donaldson WF III, Kang JD, et al: Postoperative management protocol for incidental dural tears during degenerative lumbar spine surgery: a review of 3,183 consecutive degenerative lumbar cases. Spine (Phila Pa 1976) 31:2609-2613, 2006

7. Lotan R, Al-Rashdi A, Yee A, Finkelstein J: Clinical features of conjoined lumbosacral nerve roots versus lumbar intervertebral disc herniations. Eur Spine J 19:1094-1098, 2010

8. Morgan-Hough CV, Jones PW, Eisenstein SM: Primary and revision lumbar discectomy. A 16-year review from one centre. J Bone Joint Surg Br 85:871-874, 2003

9. Sin AH, Caldito G, Smith D, Rashidi M, Willis B, Nanda A: Predictive factors for dural tear and cerebrospinal fluid leakage in patients undergoing lumbar surgery. J Neurosurg Spine 5:224-227, 2006
10. Stolke D, Sollmann WP, Seifert V: Intra- and postoperative complications in lumbar disc surgery. Spine (Phila Pa 1976) 14:56-59, 1989

11. Wang JC, Bohlman HH, Riew KD: Dural tears secondary to operations on the lumbar spine. Management and results after a two-year-minimum follow-up of eighty-eight patients. J Bone Joint Surg Am 80:1728-1732, 1998

12. Williams BJ, Sansur CA, Smith JS, Berven SH, Broadstone PA, Choma TJ, et al: Incidence of unintended durotomy in spine surgery based on 108,478 cases. Neurosurgery 68:117-124, 2011

13. Wiltse LL, Berger PE, McCulloch JA: A system for reporting the size and location of lesions in the spine. Spine (Phila Pa 1976) 22:1534-1537, 1997

\section{Author Contributions}

Conception and design: Smorgick, Baker, Herkowitz, Bachison, Fischgrund. Acquisition of data: Smorgick, Herkowitz, Montgomery, Badve, Bachison, Ericksen, Fischgrund. Analysis and interpretation of data: Smorgick. Drafting the article: Smorgick, Fischgrund. Critically revising the article: Baker, Fischgrund. Reviewed submitted version of manuscript: Montgomery, Badve, Bachison. Approved the final version of the manuscript on behalf of all authors: Smorgick. Statistical analysis: Baker. Administrative/technical/material support: Baker. Study supervision: Herkowitz, Montgomery, Fischgrund.

\section{Correspondence}

Yossi Smorgick, William Beaumont Hospital, 3535 W. 13 Mile Rd., Ste. 744, Royal Oak, MI 48073. email: noam_yossi@yahoo. com. 